\title{
Patient complaints in general practice seen through the lens of professionalism: a retrospective observational study
}

\section{Pieter C Barnhoorn, MD ${ }^{1 *}$, Geurt TJM Essers, MSc, PhD², Vera Nierkens, MSc, $\mathrm{PhD}^{1}$, Mattijs E Numans, MD, PhD ${ }^{1}$, Walther NKA van Mook, MD, PhD ${ }^{3,4}$, Anneke WM Kramer, MD, PhD ${ }^{1}$}

${ }^{1}$ Department of Public Health and Primary Care, Leiden University Medical Center, Leiden, The Netherlands; ${ }^{2}$ The Netherlands' Network of the GP Specialty Training Institutes, Utrecht, The Netherlands; ${ }^{3}$ Department of Intensive Care Medicine and Academy for Postgraduate Medical Training, Maastricht University Medical Centre, Maastricht, The Netherlands; ${ }^{4}$ School of Health Professions Education, Maastricht University, Maastricht, The Netherlands

\begin{abstract}
Background: Professionalism is a key competence for physicians. Patient complaints provide a unique insight into patient expectations regarding professionalism. Research exploring the exact nature of patient complaints in general practice, especially focused on professionalism, is limited.
\end{abstract}

Aim: To characterise patient complaints in primary care and to explore in more detail which issues with professionalism exist.

Design \& setting: A retrospective observational study in which all unsolicited patient complaints to a representative out-of-hours general practice (OOH GP) service provider in The Netherlands were analysed over a 10-year period (2009-2019).

*For correspondence: P.C. Barnhoorn@lumc.nl

Competing interest: The authors declare that no competing interests exist.

Received: 17 October 2020 Accepted: 13 November 2020 Published: 14 April 2021

(C)This article is Open Access: CC BY license (https://creativecommons.org/licenses/by/4.0/)

Author Keywords: general practice, after-hours care, patient complaints, retrospective observational studies, professionalism, professional development, professional identity formation

Copyright (C) 2021, The Authors; DOI:10.3399/BJGPO.2020.0168
Method: Complaints were coded for general characteristics and thematically categorised using the CanMEDS Physician Competency Framework (CanMEDS) as sensitising concepts. Complaints categorised as professionalism were subdivided using open coding.

Results: Out of 746996 patient consultations (telephone, face-to-face, and home visits) 484 (0.065\%) resulted in eligible complaint letters. The majority consisted of two or more complaints, resulting in 833 different complaints. Most complaints concerned GPs (80\%); a minority (19\%) assistants. Thirtyfive per cent concerned perceived professionalism lapses of physicians. A rich diversity in the wording of professionalism lapses was found, where 'not being taken seriously' was mentioned most often. Forty-five per cent related to medical expertise, such as missed diagnoses or unsuccessful clinical treatment. Nineteen per cent related to management problems, especially waiting times and access to care. Communication issues were only explicitly mentioned in $1 \%$ of the complaints.

Conclusion: Most unsolicited patient complaints were related to clinical problems. A third, however, concerned professionalism issues. Not being taken seriously was the most frequent mentioned theme within the professionalism category.

\section{How this fits in}

Research exploring the exact nature of patient complaints in general practice, especially focusing on professionalism, is limited. It was found that one-third of unsolicited patient complaints concerned professionalism issues. In addition, a rich diversity in the wording of professionalism lapses was found, 
where 'not being taken seriously' was mentioned most often. By staying close to the words that patients use, the richness of the lessons that can be learnt from patient complaints can be preserved. These lessons provide important opportunities to improve GP care and GP training.

\section{Introduction}

Professionalism is a key competence for all physicians. ${ }^{1}$ Lapses in physicians' professionalism may affect health outcomes, therapeutic relationships, and the public's perception and trust in the medical profession. ${ }^{1-8}$ Perceived professionalism lapses are part of patient complaints in all healthcare settings. ${ }^{6,9-13}$ GPs are especially vulnerable to patient complaints. ${ }^{13-16}$

Patient complaints provide unique and important insights into people's expectations, especially as unsolicited complaints contain spontaneously provided information reflecting issues that are of high importance to patients and are not being captured otherwise. ${ }^{5,6,10,17}$ Complaints reflect patients' expectations about provided care, especially concerning professionalism. Therefore, complaints are increasingly recognised as a potentially valuable source of information for improving healthcare quality. ${ }^{6,7,9,18-20}$ However, the exact relationship between complaints and quality of care is complex. Not all adverse events or all instances of patient dissatisfaction lead to complaints. ${ }^{20,21}$ Moreover, patient dissatisfaction may lead to complaints even when provided care has been exemplary. ${ }^{20,21} \mathrm{~A}$ further challenge in research on patient complaints is that professionalism issues may appear in many guises and can even be reflected in complaints if not explicitly mentioned. ${ }^{4,7,9-11}$ Moreover, when coding complaints using a standardised format, there is a danger of losing the richness of lessons that can be learnt from patient complaints. ${ }^{10,22}$ Research on patient complaints has the potential to address these challenges.

The exact nature of professionalism lapses often goes unnoticed because a universally agreed definition of professionalism is missing. ${ }^{23-30}$ Aspects of professionalism have been defined in terms of virtues (the good physician as a person of character) or behaviour (the good physician as a person who demonstrates competence). ${ }^{27,29,31}$ In the authors' view, CanMEDS, the General Medical Council (GMC) guidance, and the Ottawa Working Group on Professionalism provide sufficient direction for research on professionalism, as does research that describes and classifies unprofessional behaviours. ${ }^{32-36}$ However, what people expect of physicians regarding professionalism and what they consider lapses in professionalism need to be researched.

It should be acknowledged that professionalism can have different meanings in different contexts. ${ }^{6,28,37-40}$ Most research on what is perceived as (un)professional behaviour has hitherto been conducted in hospital settings. ${ }^{2-7,41}$ These studies found that most complaints are about medical, organisational, and communication issues as well as lapses in professionalism. 2,4-7,19 Whether these findings are generalisable to settings outside the hospital is under-researched. ${ }^{2-7,41}$ Research focused on professional lapses in the GP context needs to be especially broadened and deepened, as previous research lacks the qualitative richness that patient complaints deserve. ${ }^{13,19,42-45}$ In OOH GP care, neither the patient nor the GP can benefit from a long-lasting relationship (in regular GP patient care this commonly exists); therefore, it is expected that professionalism lapses that may go unnoticed in regular GP care emerge more clearly in the $\mathrm{OOH}$ setting. The $\mathrm{OOH}$ context requires the utmost of a GP's professionalism. ${ }^{19,44,46,47}$

Summarising the exact nature of patient complaints, in particular the perceived professional lapses, often remains enigmatic and unexplored, especially in the GP context. This study, therefore, aimed to answer the following research questions:

1. How can patient complaints in the GP setting be characterised?

2. What elements of physicians' professionalism do patients address in these complaints?

\section{Method}

To investigate the exact nature of patient complaints in OOH GP care, with a special focus on perceived professionalism lapses of physicians, a detailed content analysis was performed of original unsolicited patient complaints lodged at an $\mathrm{OOH}$ GP centre. The original patient complaints were used in order to stay close to the words that patients used, aiming to preserve the richness of lessons that can be learnt from patient complaints. 


\section{Study context}

The Dutch healthcare system is funded by a combination of tax contributions and a compulsory health insurance consisting of a per capita payment and fee-for-service. GPs are responsible for patients enlisted in their practice $24 / 7$. On weekdays between 8.00 am and 5.00 pm primary medical health care is delivered by the GP practice. Outside office hours care is outsourced to the local OOH GP centres. Here, GPs answer emergency calls, offer consultations, and arrange home visits. ${ }^{48}$ The $\mathrm{OOH}$ GP cooperative in the present study (GP Services Rijnland) consists of three $\mathrm{OOH}$ GP care clinics. These clinics provide care for patients enlisted in GP practices in eight municipalities in both rural and (sub)urban areas, adding up to 325000 inhabitants. These three clinics provide 75000 calls, consultations, and home visits annually. If patients are dissatisfied with their care, they can lodge a complaint, either written, by email, telephone, or face to face, in a robust complaint system managed by a complaints officer.

\section{Study design and procedure}

In this retrospective observational study, a content analysis was performed of all unsolicited healthcare complaints lodged at the OOH GP centre between 2009 and 2019, and all related relevant correspondence. For the purpose of this study, a complaint letter was defined as a letter (or transcript of a telephone or face-to-face encounter) that addresses one or more type of wrongdoing, offence, grievance, or resentment arising from the offered $\mathrm{OOH}$ GP service. A complaint was defined as every separately distinguishable type of wrongdoing, offence, grievance, or resentment that could be distilled from a complaint letter.

The original complaint letters were retrieved from storage, anonymised, and digitalised by the OOH GP complaints officer.

Excel software was used to organise the data. Descriptive statistics were used for quantitative analysis of the codes and categories. The STROBE guidelines were used in the conduct and reporting of this study. ${ }^{49}$ The study was performed in three steps.

The members of the research team were purposefully sampled to prevent blind spots in the analysis. All authors work as educational researchers and medical educators; four authors are clinicians, three are GPs. Walter NKA van Mook is an intensivist, Geurt TJM Essers is a psychologist, and Vera Nierkens is a health scientist specialised in health behaviour.

\section{Data analysis step 1: general characteristics}

Where identifiable, the OOH GP complaints officer recorded: the sex and age of the patient whom the complaints concerned; whether the complainant was the patient in question, a relative, or another person involved (for example, the patient's legal representative); to whom the complaint was directed (GP, GP resident, or the assistant); and how the complaint was submitted (by letter, email, telephone, or face to face).

\section{Data analysis step 2: themes}

The first round of content coding of the anonymised original letters was open, inductive, and done with an iterative, constant comparison approach. Two authors analysed 25 randomly chosen transcripts and discussed their initial open coding. Distinct codes were assigned to each remark referring to different contents of the complaint. If a complaint letter concerned $>1$ aspect of care, each complaint was coded separately. Hereafter, one author analysed all 2009 and 2010 complaint letters $(n=90)$ and the open coding was discussed again. Two authors sought and found consensus on the axial coding scheme, which was then cross-checked with two other researchers. Subsequently, two authors performed selective coding, categorising the different codes into more abstract themes. Consensus on the themes was reached within the whole research team after two rounds of discussion. As the abstract themes paralleled the CanMEDS competencies, these competencies were used as sensitising concepts in a second round of deductive coding..$^{33}$ It was decided to assign all complaints that could not clearly be categorised in one of the other six CanMEDS competencies to professionalism so as not to miss any authentic patient information.

Although data saturation was reached prior to finishing coding, all complaints were coded to ensure that the results accurately represented the frequencies and themes of the patient complaints. 
Table 1 General characteristics of complaints

\begin{tabular}{|c|c|c|c|c|}
\hline Medium, n (\%) & Complainant, $n$ (\%) & Aimed at, $n(\%)^{a}$ & Sex, $n(\%)$ & Age, years, $n(\%)$ \\
\hline Email or letter, 362 (75) & Patient, 198 (41) & GP, 389 (80) & Female, 259 (56) & $0-18,104(31)$ \\
\hline Telephone, 116 (24) & Parent, 147 (30) & Assistant, 90 (19) & Male, 206 (44) & $19-64,150(45)$ \\
\hline \multirow[t]{3}{*}{ Face to face, 6 (1) } & Partner, 63 (13) & Organisation, 49 (10) & Missing, 19 (4) & $\geq 65,77(23)$ \\
\hline & Child, 54 (11) & Resident, 6 (1) & & Missing, 153 (32) \\
\hline & Other, 22 (5) & & & \\
\hline Total, 484 (100) & Total, $484(100)$ & Total, $484(100)$ & Total, 484 (100) & Total, 484 (100) \\
\hline
\end{tabular}

aSome complaints were aimed at more than one person.

\section{Data analysis step 3: professionalism}

In order to answer research question 2, a deeper open analysis was conducted of the complaints coded as professionalism. It was also analysed whether these professionalism-related complaints stood on their own or were mentioned in combination with other complaints and vice versa.

\section{Results}

Over the 10-year study period 746996 patient consultations took place. The annual number varied between 70853 (2013) and 84410 (2018). These telephone contacts, face-to-face GP consultations, and home visits resulted in 493 complaint letters lodged. Three proved registrations of adverse events, five were addressed to healthcare professionals not in $\mathrm{OOH} \mathrm{GP} \mathrm{care} \mathrm{services,} \mathrm{and} \mathrm{one} \mathrm{lacked} \mathrm{detailed}$ information, hampering further analysis. Consequently, nine complaint letters were excluded and 484 original complaint letters (concerning $0.065 \%$ of total consultations, annual percentage ranging from $0.059 \%$ to $0.161 \%$ ) were analysed.

\section{General characteristics}

The vast majority of the complaints $(n=362)$ were submitted by letter or email $(75 \%), 116$ by telephone (24\%), and six in a face-to-face meeting (1\%) (Table 1).

Complaints were submitted by patients themselves (41\%), their parents $(30 \%)$, their partners $(13 \%)$, or their children $(11 \%)$. The remaining $5 \%$ were lodged by other relatives and colleagues. Most complaints were about GPs (80\%). In $19 \%$ of complaints, the $\mathrm{OOH}$ GP care centre assistant

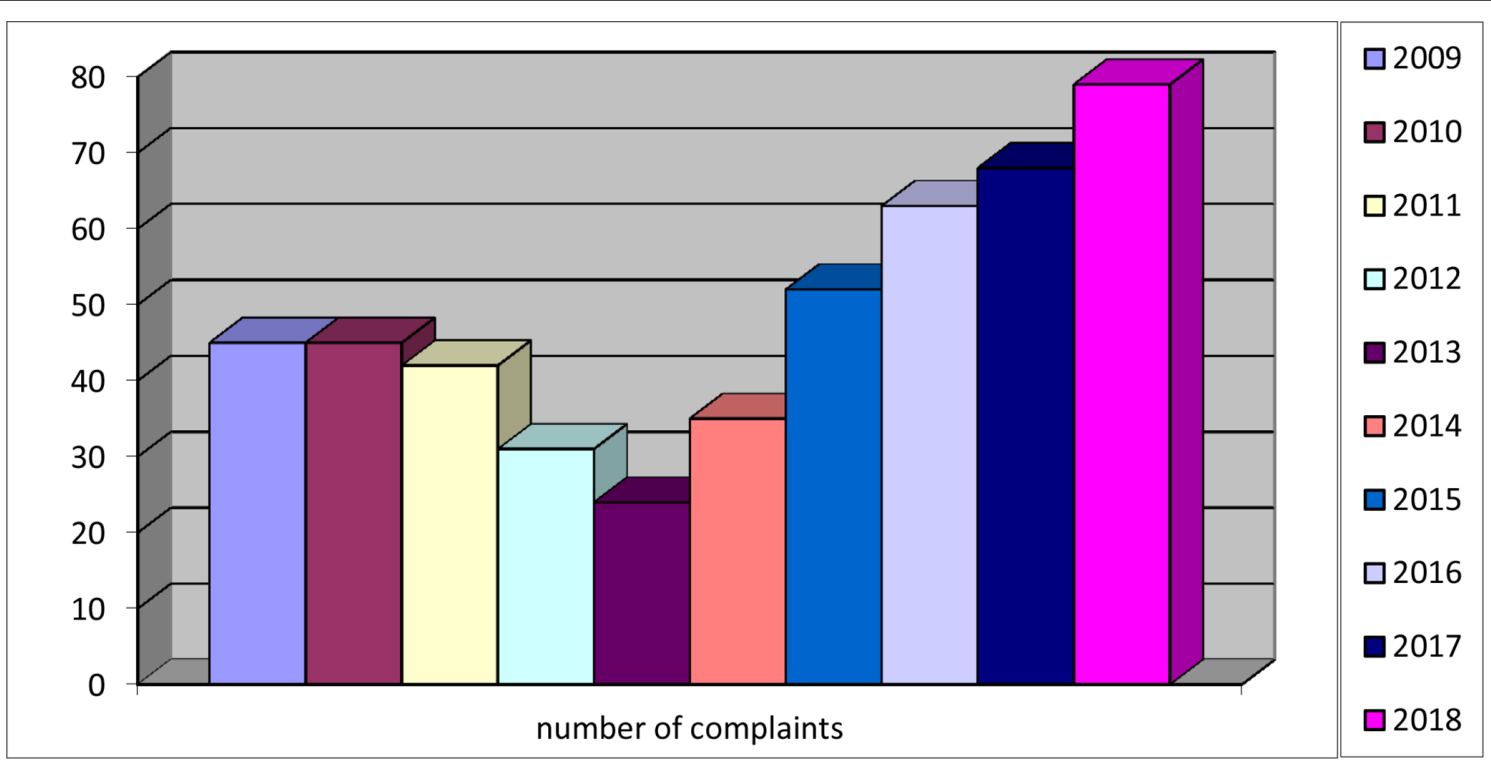

Figure 1 Number of complaints per year 
Table 2 Complaint themes except professionalism

\begin{tabular}{|c|c|c|c|}
\hline $\begin{array}{l}\text { Sensitising con- } \\
\text { cept }\end{array}$ & Theme & $n(\%)$ & Exemplary quotations (complaint identifier) \\
\hline \multirow[t]{3}{*}{ Medical expertise } & Missed diagnosis & $177(21)$ & 'Eventually, the toe turned out to be broken after all.' (1120) \\
\hline & & & $\begin{array}{l}\text { 'Because of persistent complaints, my own doctor later referred me to the cardiologist, who } \\
\text { diagnosed myocardial infarction.' (1003) }\end{array}$ \\
\hline & & & $\begin{array}{l}\text { 'The following day, my appendix was found to be inflamed and I had to have an operation } \\
\text { immediately.' (1431) }\end{array}$ \\
\hline \multirow[t]{2}{*}{ Medical expertise } & Insufficient medical examination & $99(12)$ & $\begin{array}{l}\text { 'He only felt with two fingers whether there was a temperature difference. Furthermore, he } \\
\text { didn't perform any physical examination.' (1739) }\end{array}$ \\
\hline & & & 'I was briefly examined and then dismissed.' (1853) \\
\hline \multirow[t]{2}{*}{ Medical expertise } & $\begin{array}{l}\text { Poor or unsuccessful clinical } \\
\text { treatment }\end{array}$ & $71(9)$ & 'However, placing the catheter had no effect.' (1427) \\
\hline & & & $\begin{array}{l}\text { 'The anaesthetics did not go smoothly; the anaesthetic fluid came out through the wound and } \\
\text { did not work.' (1808) }\end{array}$ \\
\hline Managing & Long waiting time for care & $55(7)$ & $\begin{array}{l}\text { 'After three hours, there was still no doctor and the pain became unbearable for my wife.' } \\
\text { (1006) }\end{array}$ \\
\hline \multirow[t]{2}{*}{ Managing } & Refusal to visit or consult & $47(6)$ & $\begin{array}{l}\text { 'A doctor can never make a diagnosis over the phone! After repeatedly emphasising that it } \\
\text { was really impossible to come to the clinic, the doctor even started a discussion.' (1202) }\end{array}$ \\
\hline & & & 'We had to wait over an hour in the waiting room.' (1868) \\
\hline \multirow[t]{2}{*}{ Medical expertise } & $\begin{array}{l}\text { Outdated, wrong, or absent } \\
\text { advice }\end{array}$ & $29(3)$ & 'Further advice was not given, so a restful sleep was not an option.' (0944) \\
\hline & & & 'When asked by my own doctor, this advice turned out to be incorrect.' (1739) \\
\hline Managing & Finance and billing & $17(2)$ & $\begin{array}{l}\text { 'She received no advice during the phone call, on the contrary, the call was broken off for no } \\
\text { reason at all. Because of this, we are unpleasantly surprised to have to pay an amount of } 25 \\
\text { euros and request a remission of the amount.' (1823) }\end{array}$ \\
\hline Communication & Not called back & $5(1)$ & $\begin{array}{l}\text { 'My brother was then informed that he would be called back by the doctor within } 10 \text { minutes } \\
\text { about the situation. However, he has not been called back at all!' (1701) }\end{array}$ \\
\hline
\end{tabular}

was involved. Ten per cent of complaints were directed against the organisation of the OOH GP care centre. In six complaints (1\%), the GP resident was explicitly mentioned as transgressing. The sex of the patient was not mentioned in 19 complaints (4\%). Of the remaining 465 complaints, 259 (56\%) related to female patients and $206(44 \%)$ to male patients. The age of the patient was known in 331 complaint letters (68\%). Of these, 104 were aged $0-18$ years (31\%), 150 were aged $19-64$ years (45\%), and 77 were aged $\geq 65$ years $(23 \%)$.

After an initial decline in the number of complaints, an increase was observed from 24 complaints in 2013 to 79 complaints in 2018 (Figure 1). This absolute increase was accompanied by an increase in relative numbers.

Half of the complaint letters (49\%) concerned one single complaint (data not shown). The remaining half concerned two or more complaints. In six cases there were up to five different complaints lodged at the same time. In total, out of the 484 analysed complaint letters, 833 different complaints could be distilled.

\section{Themes}

Table 2 shows all complaint themes except those about professionalism. A total of 376 concerned medical expertise $(45 \%)$, for example, missed diagnoses (predominantly missed fractures, myocardial infarction, and appendicitis), insufficient medical examination, poor or unsuccessful clinical treatment (such as incorrect placement of catheters or suboptimal stitching) and outdated, wrong, or absent advice. One hundred and nineteen complaints pertained to management issues (14\%), for example, long waiting time for care, refusal to visit or consult, and finance and billing. Five complaints were solely about communication (1\%), for example, not being called back. The remaining 333 complaints (40\%) could not be clearly categorised in the above-mentioned CanMEDS competencies, that is, medical expert, manager and communicator, nor in the competencies collaborator, health advocate, 
Table 3 Explanatory quotes about complaints pertaining to professionalism

\begin{tabular}{ll}
\hline Themes & Explanatory quote \\
\hline Not taken seriously & 'I am really angry that my complaint was not taken seriously.' (1130) \\
'I am very angry that I was not taken seriously and have been dismissed as a \\
hysterical person.' (0913) \\
'Then, the doctor said: "and what was the urgent problem again?"' (1108) \\
'What are you doing here? You have only had troubles for a few days now, and \\
the OOH GP is only for emergency care.' (1452) \\
'The doctor cannot find anything wrong and said: "You just have a cry-baby."' \\
(1136) \\
$\begin{array}{ll}\text { 'Then, we were told that we were absolutely not allowed to consult the OOH } \\
\text { GP for these complaints.' (0919) }\end{array}$ \\
\hline 'The doctor did not answer my questions, but barked at me.' (1008) \\
\hline Spoken to unpleasantly & 'This comment was extremely out of place at that time.' (1305) \\
\hline Inappropriate comment & 'She examined her with a total lack of empathy.' (1105) \\
\hline Lack of empathy & 'I got the feeling that she was in a great hurry.' (1311) \\
\hline Rushed & 'The doctor did not introduce himself.' (1754) \\
\hline No introduction & 'He did not shake my hand upon entering.' (1106) \\
\hline Not shaking hands & 'The doctor's attitude was arrogant and disrespectful.' (1413) \\
\hline Arrogant & 'The doctor was sleepy, inattentive, and uninterested.' (1763) \\
\hline Uninterested & 'The doctor was very hard-handed.' (0901) \\
\hline Physical harshness & Mn daughter felt she was touched in an unpleasant way.' (1435) \\
\hline Unwanted intimacy &
\end{tabular}

or scholar, and were preliminary coded as professionalism. After analysing all 2009 and 2019 complaint letters $(n=90)$, no new themes emerged.

\section{Professionalism}

The 333 complaints coded under 'professionalism' were explored in more detail. Of these 333 complaints, 290 were indeed about perceived lapses in physicians' professionalism. The remaining 43 complaints were all found to be directed specifically against the organisation of the $\mathrm{OOH}$ GP care centre (for example, unhygienic working environment, insufficient or unclear signage, or non-medical advertising brochures in the waiting room) or the $\mathrm{OOH}$ GP care centre assistant (for example, unclear information about the clinic's address and asking more information than necessary). These complaints were not investigated further, as they fell outside the scope of this study.

Patients articulated the perceived lapses in physicians' professionalism in different terms. Examples included the following: not being taken seriously; being patronised; being unpleasantly spoken to; receiving inappropriate comments; perceiving a lack of empathy; perceiving the physician as being rushed; a physician who does not introduce himself or herself; not shaking hands; a physician who appears arrogant or uninterested; or displays physical harshness or unwanted intimacy. Table 3 shows explanatory quotes. The theme most frequently found within the professionalism category was 'not being taken seriously' ( $n=88$ ), mostly in regard to the health issue itself, the urgency, or the perception that one was seen as being overprotective.

Of the 484 complaint letters, 213 contained complaints concerning lapses in professionalism, which in $87(41 \%)$ cases was the only complaint. In $61(29 \%)$ cases, a lapse in professionalism was combined with missed diagnoses, in $38(18 \%)$ cases with insufficient medical examination, and in $19(9 \%)$ cases with long waiting time for care.

\section{Discussion}

\section{Summary}

All patient complaint letters lodged at an OOH GP centre were thoroughly analysed with a special focus on perceived unprofessional behaviour of physicians. It was found that $746996 \mathrm{OOH}$ GP consultations 
over a 10-year period resulted in 484 complaint letters pertaining to healthcare professionals. Over one-third (35\%) of the patient complaints concerned perceived lapses in physicians' professionalism. A rich diversity in the wording of professionalism lapses was found, of which not being taken seriously was mentioned most often.

\section{Strengths and limitations}

To the authors' knowledge, the present study is the first to use content analysis of patient complaints in the context of primary care focused on GPs' professionalism lapses. Moreover, the study period of a decade and the large number of complaint letters that could be analysed are unique. The $\mathrm{OOH}$ GP centre under study covers a large, diverse, and representative population of patients, which contributes greatly to generalisability of the results.

A few limitations should be noted. Notwithstanding the robust complaint system, not all adverse events or instances of patient dissatisfaction may lead to complaints. ${ }^{20,21}$ Moreover, complaints may be biased by negative health outcomes, as these outcomes may lead to patient dissatisfaction even when provided care has been exemplary. ${ }^{20,21}$ As in every analysis, information can get lost in translation to abstract themes. However, using a two-step analysis with both inductive and deductive methods, and multiple coding added to the rigour of this study.

\section{Comparison with existing literature}

The data show a steady increase in patient complaints since 2013. This is in contrast with a recent study by Wallace et al on patient complaints in $\mathrm{OOH} \mathrm{GP}$, in which a relatively stable annual rate was seen of around $0.061 \%$ over a 5 -year period, but is in line with other studies. ${ }^{19,50,51}$ Reasons for a potential increase, as mentioned in the literature, include a broader cultural change in society, including: changing expectations, nostalgia for a 'golden age' of health care, and the desire to raise grievances altruistically. ${ }^{52,53}$ This is in line with the many statements made in the complaint letters in the present study about the 'desire for openness' and the 'hope that this won't happen to others in the future'. The other general characteristics (medium, complainant, and aim) are consistent with the existing literature. $4,6,9,10,19$ This also applies to the frequency distribution that was found, with most complaints being about the medical expert role followed by complaints about professionalism and management. ${ }^{5,7,10,13}$

The results match well with Reader et al's taxonomy for patient complaints and their ensuing Healthcare Complaints Analysis Tool (HCAT). ${ }^{10,22}$ Previous research using the HCAT for patient complaints in an $\mathrm{OOH}$ GP setting confirms the usability of this taxonomy in the (OOH) GP setting, although it is primarily based on research in hospital settings. ${ }^{10,19,51}$ However, the 290 complaints about perceived lapses in physicians' professionalism could be placed in at least four categories of the HCAT (respect and patient rights, listening, communication, and quality). ${ }^{10,22}$ Therefore, a deeper analysis of patients' rich vocabulary regarding professionalism was performed, which aimed to explore what people expect of physicians regarding professionalism and what they consider lapses in professionalism. The authors aimed to stay close to the words that patients used (not being taken seriously, being patronised, being unpleasantly spoken to, and so on) to avoid losing the essence of the complaint in the translation to more abstract predefined themes. This provided unique and important insights into patients' expectations and their feelings about the provided care, especially concerning professionalism, which allows us to learn from these complaints. ${ }^{4,6,7,9-12,19,20}$

The percentage of what were considered lapses in professionalism (35\%) is average and in line with the existing literature. Mattarozzi et al found relationship aspects to be the cause of complaint in $52.8 \%$ cases. ${ }^{7}$ Wofford et al found disrespect, with $36 \%$, their most identified category. ${ }^{4}$ In their extensive review on 59 studies, reporting 88069 patient complaints, Reader et al found that $29.1 \%$ related to healthcare staff-patient relationships. Contrarily, Schnitzer et al found that only a relative proportion of $9.3 \%$ of complaints were about the physician-patient relationship. ${ }^{9}$ However, it is thought the percentage of lapses in professionalism might even be higher because professionalism can be expressed via the performance of other competences. ${ }^{54}$ This could explain the relatively high percentage of combinations of competencies that were complained about in one complaint letter. 


\section{Implications for research and practice}

In line with most of the other literature on patient complaints, the results show that unmet expectations were a driver for many complaints. ${ }^{5-7,11,13,19,41,44,55}$ Therefore, GPs and future GPs have to be informed that they need to actively address patient expectations during consultations. They need to communicate about examination, treatment, potential complications, and prognosis. ${ }^{19}$

In postgraduate medical education and continuing medical education training, attention should be paid to the fact that professionalism lapses often occur and that these lapses can have a wide range of devastating consequences. ${ }^{1-8}$ By analysing patient complaints using CanMEDS, the authors want to facilitate the implementation in GP training. The findings of this study provide direction and underline the utter importance of (bi-directional) direct observation of residents by their supervisors in the $\mathrm{OOH}$ GP setting. ${ }^{56}$

Further research should focus on deeper analysis of complaints concerning professionalism, because perceived lapses in professionalism are frequently complained about but are articulated by patients in different ways. In-depth interviews are needed to further investigate the subtleties of how lapses in professionalism are perceived. ${ }^{54}$

\section{Funding}

The study did not receive any funding.

\section{Ethical approval}

This study was approved by the Medical Ethics Committee of the Leiden University Medical Centre (file number: G17.100).

Provenance

Freely submitted; externally peer reviewed.

\section{References}

1. Cruess RL, Cruess SR, Steinert Y. Teaching medical professionalism: supporting the development of a professional identity. Cambridge: Cambridge University Press; 2016.

2. Saha R, Kabanovski A, Klejman S, et al. Patients' complaints involving ophthalmologists in the province of Ontario, Canada: a 5-year review. Can J Ophthalmol 2020; 55(3 Suppl 1): 22-26. DOI: https://doi.org/10.1016/j.jcjo.2019. 08.007

3. Catron TF, Guillamondegui OD, Karrass J, et al. Patient complaints and adverse surgical outcomes. Am J Med Qual 2016; 31(5): 415-422. DOI: https://doi.org/10.1177/1062860615584158

4. Wofford MM, Wofford JL, Bothra J, et al. Patient complaints about physician behaviors: a qualitative study. Acad Med 2004; 79(2): 134-138. DOI: https://doi.org/10.1097/00001888-200402000-00008

5. Montini T, Noble AA, Stelfox HT. Content analysis of patient complaints. Int J Qual Health Care 2008; 20(6): 412-420. DOI: https://doi.org/10.1093/intqhc/mzn041

6. van Mook WNKA, Gorter SL, Kieboom W, et al. Poor professionalism identified through investigation of unsolicited healthcare complaints. Postgrad Med J 2012; 88(1042): 443-450. DOI: https://doi.org/10.1136/postgradmedj2011-130083

7. Mattarozzi K, Sfrisi F, Caniglia F, et al. What patients' complaints and praise tell the health practitioner: implications for health care quality. A qualitative research study. Int J Qual Health Care 2017; 29(1): 83-89. DOI: https://doi.org/ 10.1093/intqhc/mzw139

8. Aguilar AE, Stupans L, Scutter S. Assessing students' professionalism: considering professionalism's diverging definitions. Educ Health 2011; 24(3): 599.

9. Schnitzer S, Kuhlmey A, Adolph H, et al. Complaints as indicators of health care shortcomings: which groups of patients are affected? Int J Qual Health Care 2012; 24(5): 476-482. DOI: https://doi.org/10.1093/intqhc/mzs036

10. Reader TW, Gillespie A, Roberts J. Patient complaints in healthcare systems: a systematic review and coding taxonomy. BMJ Qual Saf 2014; 23(8): 678-689. DOI: https://doi.org/10.1136/bmjqs-2013-002437

11. Kravitz RL, Callahan EJ, Paterniti D, et al. Prevalence and sources of patients' unmet expectations for care. Ann Intern Med 1996; 125(9): 730-737. DOI: https://doi.org/10.7326/0003-4819-125-9-199611010-00004

12. Koetsier E, Boer C, Loer SA. Complaints and incident reports related to anaesthesia service are foremost attributed to nontechnical skills. Eur J Anaesthesiol 2011; 28(1): 29-33. DOI: https://doi.org/10.1097/EJA.0b013e32833e364c

13. Owen C. Formal complaints against general practitioners: a study of 1000 cases. Br J Gen Pract 1991; 41(344): 113-115.

14. Tazzyman A, Bryce M, Walshe K, Boyd A. Identifying and managing concerns about GPs in England: an interview study and case-series analysis. Br J Gen Pract 2019; 69(684): e499-e506. DOI: https://doi.org/10.3399/ bjgp19X703733 
15. Liu JJ, Alam AQ, Goldberg HR, et al. Characteristics of internal medicine physicians disciplined by professional colleges in Canada. Medicine 2015; 94(26): e937. DOI: https://doi.org/10.1097/MD.0000000000000937

16. Cunningham $\mathrm{W}$, Crump $\mathrm{R}$, Tomlin $\mathrm{A}$. The characteristics of doctors receiving medical complaints: a cross-sectional survey of doctors in New Zealand. N Z Med J 2003; 116(1183): U625.

17. Gillespie A, Reader TW. The Healthcare Complaints Analysis Tool: development and reliability testing of a method for service monitoring and organisational learning. BMJ Qual Saf 2016; 25(12): 937-946. DOI: https://doi.org/10. 1136/bmjqs-2015-004596

18. Behrens R. Handling complaints: harnessing feedback to improve services. Br J Gen Pract 2018; 68(675): 483. DOI: https://doi.org/10.3399/bjgp18X699185

19. Wallace $\mathrm{E}$, Cronin S, Murphy N, et al. Characterising patient complaints in out-of-hours general practice: a retrospective cohort study in Ireland. Br J Gen Pract 2018; 68(677): e860-e868. DOI: https://doi.org/10.3399/ bjgp18X699965

20. Cunningham W, Wilson H. Complaints, shame and defensive medicine. BMJ Qual Saf 2011; 20(5): 449-452. DOI: https://doi.org/10.1136/bmjqs.2011.051722

21. Bismark MM, Brennan TA, Paterson RJ, et al. Relationship between complaints and quality of care in New Zealand: a descriptive analysis of complainants and non-complainants following adverse events. Qual Saf Health Care 2006; 15(1): 17-22. DOI: https://doi.org/10.1136/qshc.2005.015743

22. Gillespie A, Reader TW. Healthcare Complaints Analysis Tool, version 3, 2015. 2015; https://qualitysafety.bmj.com/ content/suppl/2016/01/05/bmjqs-2015-004596.DC1/bmjqs-2015-004596supp_new.pdf (accessed 24 Mar 2021).

23. Barnhoorn PC. Professional behavior: to define is to limit. Acad Med 2016; 91(9): 1192-1193. DOI: https://doi.org/ 10.1097/ACM.0000000000001306

24. Barnhoorn PC, van Mook WNKA. Professionalism or professional behaviour: no reason to choose between the two. Med Educ 2015; 49(7): 740. DOI: https://doi.org/10.1111/medu.12650

25. Barnhoorn PC, Youngson C. Refining a definition of medical professionalism. Acad Med 2014; 89(12): 1579. DOI: https://doi.org/10.1097/ACM.0000000000000527

26. DeAngelis CD. Medical professionalism. JAMA 2015; 313(18): 1837-1838. DOI: https://doi.org/10.1001/jama.2015. 3597

27. Irby DM, Hamstra SJ. Parting the clouds: three professionalism frameworks in medical education. Acad Med 2016; 91(12): 1606-1611. DOI: https://doi.org/10.1097/ACM.0000000000001190

28. Ong YT, Kow CS, Teo YH, et al. Nurturing professionalism in medical schools. A systematic scoping review of training curricula between 1990-2019. Med Teach 2020; 42(6): 636-649. DOI: https://doi.org/10.1080/0142159X. 2020.1724921

29. Wynia MK, Papadakis MA, Sullivan WM, Hafferty FW. More than a list of values and desired behaviors: a foundational understanding of medical professionalism. Acad Med 2014; 89(5): 712-714. DOI: https://doi.org/10. 1097/ACM.0000000000000212

30. Birden $\mathrm{H}$, Glass $\mathrm{N}$, Wilson I, et al. Defining professionalism in medical education: a systematic review. Med Teach 2014; 36(1): 47-61. DOI: https://doi.org/10.3109/0142159X.2014.850154

31. Barnhoorn PC. Shared decision making seen through the lens of professional identity formation. Patient Educ Couns 2020; 103(7): 1446-1447. DOI: https://doi.org/10.1016/j.pec.2020.02.019

32. General Medical Council. Good medical practice. 2014; https://www.gmc-uk.org/ethical-guidance/ethicalguidance-for-doctors/good-medical-practice (accessed 24 Mar 2021).

33. Royal College of Physicians and Surgeons of Canada. CanMEDS: better standards, better physicians, better care; https://www.royalcollege.ca/rcsite/canmeds/canmeds-framework-e (accessed 24 Mar 2021).

34. Mak-van der Vossen M, van Mook W, van der Burgt S, et al. Descriptors for unprofessional behaviours of medical students: a systematic review and categorisation. BMC Med Educ 2017; 17(1): 164. DOI: https://doi.org/10.1186/ s12909-017-0997-x

35. Mak-van der Vossen M, Teherani A, van Mook W, et al. How to identify, address and report students' unprofessional behaviour in medical school. Med Teach 2020; 42(4): 372-379. DOI: https://doi.org/10.1080/0142159X.2019. 1692130

36. Hodges BD, Ginsburg S, Cruess R, et al. Assessment of professionalism: recommendations from the Ottawa 2010 conference. Med Teach 2011; 33(5): 354-363. DOI: https://doi.org/10.3109/0142159X.2011.577300

37. Veen M, Skelton J, de la Croix A. Knowledge, skills and beetles: respecting the privacy of private experiences in medical education. Perspect Med Educ 2020; 9(2): 111-116. DOI: https://doi.org/10.1007/s40037-020-00565-5

38. Barnhoorn PC, Houtlosser M, Ottenhoff-de Jonge MW, et al. A practical framework for remediating unprofessional behavior and for developing professionalism competencies and a professional identity. Med Teach 2019; 41(3): 303-308. DOI: https://doi.org/10.1080/0142159X.2018.1464133

39. Rothlind $\mathrm{E}$, Fors $\mathrm{U}$, Salminen $\mathrm{H}$, et al. The informal curriculum of family medicine - what does it entail and how is it taught to residents? A systematic review. BMC Fam Pract 2020; 21(1): 49. DOI: https://doi.org/10.1186/s12875020-01120-1

40. Jha V, Brockbank $\mathrm{S}$, Roberts $\mathrm{T}$. A framework for understanding lapses in professionalism among medical students: applying the theory of planned behavior to fitness to practice cases. Acad Med 2016; 91(12): 1622-1627. DOI: https://doi.org/10.1097/ACM.0000000000001287

41. Kee JWY, Khoo HS, Lim I, Koh MYH. Communication skills in patient-doctor interactions: learning from patient complaints. Health Professions Education 2018; 4(2): 97-106.

42. Birkeland S, Christensen RdePont, Damsbo N, Kragstrup J. Patient complaint cases in primary health care: what are the characteristics of general practitioners involved? Biomed Res Int 2013; 2013: 807204 DOI: https://doi.org/ $10.1155 / 2013 / 807204$ 
43. van Leusden M, Jongerius $\mathrm{PH}$, Hubben JH. [GPs and disciplinary procedures] Huisarts en tuchtrecht 1997-2007 (in Dutch). Den Haag: Sdu Uitgevers; 2008.

44. Gaal S, Hartman C, Giesen $P$, et al. Complaints against family physicians submitted to disciplinary tribunals in the Netherlands: lessons for patient safety. Ann Fam Med 2011; 9(6): 522-527. DOI: https://doi.org/10.1370/afm.1308

45. Hendriks A, van der Meer H. [Lessons from Disciplinary Law for GPs] Lessen uit Het tuchtrecht voor de huisarts (in Dutch). Huisarts Wet 2015; 58(4): 178-182. DOI: https://doi.org/10.1007/s12445-015-0103-8

46. Barragry RA, Varadkar LE, Hanlon DK, et al. An analytic observational study on complaints management in the general practice out of hours care setting: who complains, why, and what can we do about it? BMC Fam Pract 2016; 17: 87. DOI: https://doi.org/10.1186/s12875-016-0484-1

47. van der Horst HE, de Wit N. Redefining the core values and tasks of GPs in the Netherlands (Woudschoten 2019). Br J Gen Pract 2020; 70(690): 38-39. DOI: https://doi.org/10.3399/bjgp20X707681

48. Giesen $P$, Smits M, Huibers L, et al. Quality of after-hours primary care in the Netherlands: a narrative review. Ann Intern Med 2011; 155(2): 108-113. DOI: https://doi.org/10.7326/0003-4819-155-2-201107190-00006

49. Vandenbroucke JP, von Elm E, Altman DG, et al. Strengthening the reporting of observational studies in epidemiology (STROBE): explanation and elaboration. Ann Intern Med 2007; 147(8): W164-W194. DOI: https:// doi.org/10.7326/0003-4819-147-8-200710160-00010-w1

50. Vogel L. Patient complaints about Canadian doctors on the rise. CMAJ 2018; 190(13): E408. DOI: https://doi.org/ 10.1503/cmaj.109-5585

51. van Dael J, Reader TW, Gillespie A, et al. Learning from complaints in healthcare: a realist review of academic literature, policy evidence and front-line insights. BMJ Qual Saf 2020; 29(8): 684-695. DOI: https://doi.org/10. 1136/bmjqs-2019-009704

52. Moberly T. Rising complaints against doctors due to changed patient expectations, researchers say. BMJ 2014 349: g4754. DOI: https://doi.org/10.1136/bmj.g4754

53. Archer J, Regan de Bere S, Bryce M, et al. Understanding the rise in fitness to practise complaints from members of the public. 2014; https://www.gmc-uk.org/-/media/gmc-site-images/about/understanding-the-rise-in-fitnessto-practise-complaints-from-members-of-the-public.pdf?la=en\&hash=92CC11DDFE1782658CC96E7624D96401 9336F7E2 (accessed 24 Mar 2021).

54. Verkerk MA, de Bree MJ, Mourits MJE. Reflective professionalism: interpreting CanMEDS' "professionalism". J Med Ethics 2007; 33(11): 663-666. DOI: https://doi.org/10.1136/jme.2006.017954

55. Harrison R, Walton M, Healy J, et al. Patient complaints about hospital services: applying a complaint taxonomy to analyse and respond to complaints. Int J Qual Health Care 2016; 28(2): 240-245. DOI: https://doi.org/10.1093/ intqhc/mzw003

56. Rietmeijer CBT, Huisman D, Blankenstein AH, et al. Patterns of direct observation and their impact during residency: general practice supervisors' views. Med Educ 2018; 52(9): 981-991. DOI: https://doi.org/10.1111/ medu. 13631 